\title{
John Nash and the Organization of Stroke Care
}

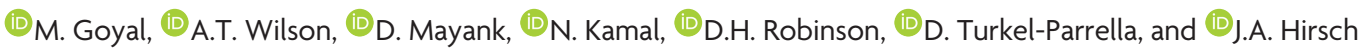

\begin{abstract}
SUMMARY: The concept of Nash equilibrium, developed by John Forbes Nash Jr, states that an equilibrium in noncooperative games is reached when each player takes the best action for himself or herself, taking into account the actions of the other players. We apply this concept to the provision of endovascular thrombectomy in the treatment of acute ischemic stroke and suggest that collaboration among hospitals in a health care jurisdiction could result in practices such as shared call pools for neurointervention teams, leading to better patient care through streamlined systems.
\end{abstract}

J ohn Forbes Nash Jr was a renowned mathematician whose groundbreaking work in the domain of game theory earned him the Nobel Prize in Economics in 1994. His theories have been key to our understanding of decision-making processes in economics and every other aspect of life involving complex strategic interactions. ${ }^{1}$

Nash became a household name due to a critically acclaimed depiction of his life in the film A Beautiful Mind. There is a scene where Nash is struck by an epiphany because of a discussion about an imaginary interaction with some young women. He realizes that Adam Smith's theory of systems fails to take into account that people choose the action that confers the greatest benefit (within the constraints of law and decency). If you have not seen the film or do not remember the scene, check it out at https://www.youtube.com/ watch?v=LJS7Igvk6ZM. The important message is that in game theory as in life, systems work best when every person does what is best for himself or herself, taking into consideration the decisions of the other players. A system in this state is in Nash equilibrium. ${ }^{2-4}$

In acute ischemic stroke due to large-vessel occlusion, we know that the natural history of the disease is generally poor and devastating, endovascular thrombectomy is highly effective, and "time is brain." ${ }^{5}$ Our biggest challenge moving forward is to improve the organization of systems of care, getting each patient to

Received October 3, 2017; accepted October 9.

From the Department of Radiology and Clinical Neurosciences (M.G., A.T.W., N.K.), University of Calgary, Calgary, Alberta, Canada; Faculty of Applied Science and Engineering (D.M.), University of Toronto, Toronto, Ontario, Canada; Department of Radiology (D.H.R.), Virginia Mason Medical Center, Seattle, Washington; Department of Neurology (D.T.-P.), Division of Neurointerventional Radiology, NYU School of Medicine, New York, New York; and Department of Neurointerventional Radiology (J.A.H.), Massachusetts General Hospital, Harvard Medical School, Boston, Massachusetts.

Please address correspondence to Mayank Goyal, MD, FRCPC, Department of Radiology, Seaman Family MR Research Centre, Foothills Medical Centre, 1403 29th St NW, Calgary AB T2N2T9, Canada; e-mail: mgoyal@ucalgary.ca

http://dx.doi.org/10.3174/ajnr.A5481 the correct hospital the first time around. ${ }^{6}$ Additionally, individual cities, jurisdictions, and groups of physicians need to organize themselves so that they can provide endovascular thrombectomy 24/7/365. Neuroinverventionists are often hired mainly on the basis of adequate availability of daytime work and where a hospital is located, the population denominator, and the presence of other neurointervention centers in the vicinity. Thus, hospitals may be limited in increasing their call pool, making the frequency of calls for each neurointerventionist quite onerous.

In game theory, a game comprises 3 parts: the players, the set of actions available to each player, and a utility function for each player. ${ }^{4}$ Here, the players are the health care providers, the actions are the choices they make regarding patient admission and treatment, and the primary utility measure of these actions is the patient's well-being. To achieve optimization (both for patient outcome and use of resources, decent call schedules, and work-life balance) based on Nash's work would require all the players (in this case, all the health care providers in a particular jurisdiction) to evaluate not only their own choices and strategy but also the choices and strategies of the other players.

Nash's work suggests that patients with stroke could be better served in their community if hospitals or neurointervention groups engaged in collaborative practices, rather than each institution working exclusively to its best interest in isolation. In this sense, each player would show his or her "hand" and, subsequently, take the best action for himself or herself based on every other player's hand. This would constitute a mutually beneficial cooperative Nash equilibrium in which the system is in a stable state, with each player maximally benefitting. ${ }^{4,7}$ In this sense, outcomes of patients with stroke (the shortest possible onset-to-reperfusion time in appropriately chosen patients ${ }^{8}$ ) will be improved in the community as a whole. 


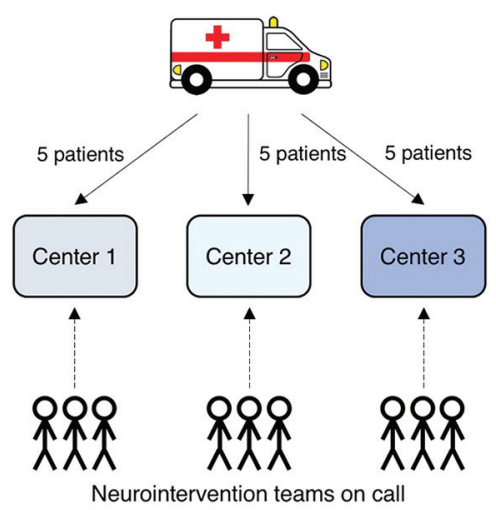

A
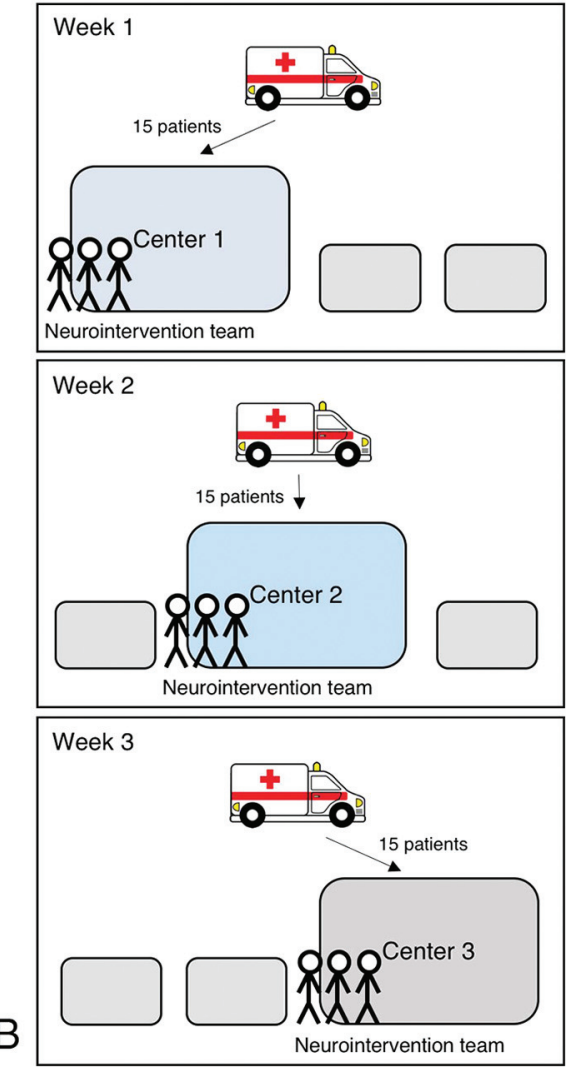

FIGURE. Schematic demonstrating different approaches to the neurointervention service for acute stroke in a community. $A$, In an isolationist setting, each stroke center has its own call schedule and receives patients. The patient volume is divided among the centers. Nearly all components of the neurointervention team are called from home. $B$, In a more cooperative setting, a call schedule is shared among the 3 centers and parts of the neurointervention team are in-house (eg, angiography nurse and technologist, stroke fellow/nurse practitioner) when that center is the active center. The active center receives a higher patient volume, making use of the neurointervention team more effective. The presence of an in-house team allows better workflow and increased efficiency. It is likely that stroke patients who are not eligible for endovascular thrombectomy (intracranial hematoma, no large-vessel occlusion) will also receive better care. Note that the total volume of patients treated by each hospital remains unchanged.

When one starts thinking this way, the obvious conclusion is to have a shared city- or jurisdiction-wide call schedule (Figure). This could be communicated well in advance to the paramedic staff so that they could determine where to bring the patient on the basis of a predetermined call schedule. In jurisdictions where many patients are brought directly to the hospital by family and friends, an alternative approach could be for the neurointerventionist on call to have privileges in all the relevant hospitals and to therefore travel to the patient. There are simple solutions to overcome the variances of catheterization laboratory setup and individual choices of tools: Physicians could carry a Brisk Recanalization Ischemic Stroke Kit (BRISK) in their cars and walk in with all the tools they need. ${ }^{9}$ Of course, establishing such a system will require cooperation and trust; however, this is easier to achieve when one is backed by a Nobel-winning mathematician's math and game theory. Is it time to start this discussion?

Disclosures: Mayank Goyal_UNRELATED: Consultancy: Medtronic, Stryker, MicroVention, Comments: teaching engagements and product advice regarding acute stroke; Grants/Grants Pending: Medtronic, Stryker, Comments: Medtronic funding for HERMES collaboration provided to the University of Calgary, Stryker funding for UNMASK EVT provided to the University of Calgary*; Patents (Planned, Pending or Issued): GE Healthcare, Comments: Systems of Stroke Diagnosis. David TurkelParrella-UNRELATED: Consultancy: Alpha Insights; Travel/Accommodations/Meeting Expenses Unrelated to Activities Listed: Stryker. Joshua A. HirschUNRELATED: Consultancy: Medtronic, Globus, Codman Neurovascular, Whale Imaging; Other Relationships: I am the recipient of a grant from the Neiman Policy Institute, where I serve as a senior affiliate research fellow. *Money paid to the institution.

\section{REFERENCES}

1. John Nash Jr.-Biographical. https://www. nobelprize.org/nobel_prizes/economicsciences/laureates/1994/nash-bio.html. Accessed September 18, 2017

2. Nash JF. Equilibrium points in N-person games. Proc Natl Acad Sci U S A 1950;36: 48-49 CrossRef Medline

3. Nash JF. Non-cooperative games. The Annals of Mathematics 1951;54:286-95 CrossRef

4. Dufwenberg M. Game theory. Wiley Interdiscip Rev Cogn Sci 2011;2:167-73 CrossRef Medline

5. Goyal M, Menon BK, van Zwam WH, et al; HERMES collaborators. Endovascular thrombectomy after large-vessel ischaemic stroke: a meta-analysis of individual patient data from five randomised trials. Lancet 2016;387:1723-31 CrossRef Medline

6. Goyal M, Jadhav AP, Wilson AT, et al. Shifting bottlenecks in acute stroke treatment. J Neurointerv Surg 2016;8:1099-100 CrossRef Medline

7. Saposni G, Johnston SC. Applying principles from the game theory to acute stroke care: learning from the prisoner's dilemma, stag-hunt, and other strategies. Int J Stroke 2016;11:274-86 CrossRef Medline

8. Menon BK, Sajobi TT, Zhang Y, et al. Analysis of workflow and time to treatment on thrombectomy outcome in the Endovascular Treatment for Small Core and Proximal Occlusion Ischemic Stroke (ESCAPE) randomized, controlled trial. Circulation 2016;133:2279-86 CrossRef Medline

9. Goyal M, Menon BK, Hill MD, at al. Consistently achieving computed tomography to endovascular recanalization < 90 minutes: solutions and innovations. Stroke 2014;45:e252-56 CrossRef Medline 